\title{
Genotyping on a Thermal Gradient DNA Chip
}

\author{
Tomoharu Kajiyama, ${ }^{1,2}$ Yuji Miyahara, ${ }^{2}$ Larry J. Kricka, ${ }^{3}$ Peter Wilding, ${ }^{3}$ \\ David J. Graves, ${ }^{4}$ Saul Surrey, ${ }^{5}$ and Paolo Fortina ${ }^{1,6}$ \\ ${ }^{1}$ Department of Pediatrics, The Children's Hospital of Philadelphia and University of Pennsylvania School of Medicine, \\ Philadelphia, Pennsylvania 19104, USA; ${ }^{2}$ Hitachi High-Technologies Corporation, Hitachinaka-shi, Ibaraki-ken, 312-8504 \\ Japan; ${ }^{3}$ Department of Pathology and Laboratory Medicine, University of Pennsylvania School of Medicine, Philadelphia, \\ Pennsylvania 19104, USA; ${ }^{4}$ Department of Chemical Engineering, University of Pennsylvania School of Engineering and \\ Applied Science, Philadelphia, Pennsylvania 19104, USA; ${ }^{5}$ Cardeza Foundation for Hematologic Research, Department of \\ Medicine, Jefferson Medical College, Thomas Jefferson University, Philadelphia, Pennsylvania 19107, USA
}

\begin{abstract}
Silicon-based chips with discrete, independently temperature-controlled islands have been developed for use in DNA microarray hybridization studies. Each island, containing a heater made of a diffusion layer and a temperature sensor based on a $\mathrm{p}-\mathrm{n}$ junction, is created on a silicon dioxide/nitride surface by anisotropic etching. Different reactive groups are subsequently added to the surface of the islands, and allele-specific oligonucleotide probes are attached to discrete spots on the chip. Hybridization is performed with Cy5-tagged single-stranded targets derived by PCR from genomic DNA. Results are assessed by measuring fluorescence of bound dye-tagged targets after hybridization and washing. Temperatures at each island can be set at different values to obtain optimal distinction between perfect matches and mismatches. This approach facilitates definition of optimal temperatures for probe/target annealing and for distinction between perfectly matched versus mismatched solution-phase targets. The thermal gradient DNA chips were then tested for genotyping, and the results for four different loci in two genes are presented. Unambiguous typing was achieved for clinically relevant loci within the factor VII and hemochromatosis genes.
\end{abstract}

Major advances have been achieved during the past 40 years in the field of microelectronics. Highly complex chips now can be fabricated by using controlled mass production processes. This has resulted in the development of inexpensive high-performance microcomputers with the ability to analyze large amounts of information. At the same time, similar rapid increases of knowledge in the fields of biochemistry and molecular biology have resulted in a need for obtaining and processing increasing amounts of biological information. We have used microfabrication and molecular biology to address this need by creating improved microfabricated biochemical sensing systems (Graves et al. 1998; Wilding et al. 1998; Kricka et al. 2002; Su et al. 2002; Yuen et al. 2002).

In the field of molecular biology, DNA chips and DNA microarrays have emerged as tools for monitoring gene expression profiles and genotyping (Case-Green et al. 1998; Lindblad-Toh et al. 2000; Carter et al. 2001; Kwok 2001; Ramaswamy et al. 2001; Syvanen 2001; Zarrinkar et al. 2001; Cai et al. 2002; Shipp et al. 2002; Su et al. 2002; Yeakley et al. 2002). The fundamental concept behind these biological tools is a massively parallel hybridization, washing, and detection process. Immobilized DNA probes on a solid surface and targets in a sample solution are brought into contact. Complementary sequences hybridize, and if the targets are fluorescently labeled, they can be identified by where the probe/ target complexes appear in the microarray. For best results, hybridization and subsequent washing to remove mismatched complexes should be done at specific temperatures.

Often, however, there are significant differences in

\section{'Corresponding author.}

E-MAIL paolo.fortina@mail.tju.edu; FAX (215) 503-2803.

Article and publication are at http://www.genome.org/cgi/doi/10.1101/ gr.790603. probe/target melting temperatures for a series of simultaneous analyses on a given microarray. This is especially true for DNA chips and DNA microarrays that use oligonucleotide probes. Although several approaches can be taken to solve this problem, such as optimization of length and composition of the probe molecules, it is, in general, difficult to find one set of conditions that is optimal for all DNA probes on a given substrate (Khrapko et al. 1991; Sosnowski et al. 1997; Gerry et al. 1999; Gilles et al. 1999; Lipshutz et al. 1999; Fan et al. 2000; Fortina et al. 2000; Hirschhorn et al. 2000; Mei et al. 2000; Pastinen et al. 2000; Cutler et al. 2001; Dong et al. 2001; Jobs et al. 2002). We have constructed a new DNA chip in which the temperature at each DNA probe location can be controlled independently. The fundamental characteristics of a thermal gradient DNA chip and its application to single nucleotide polymorphism (SNP) analyses/mutation detection are described in this report.

\section{RESULTS}

\section{Structure of Thermal Gradient DNA Chip}

Thermal gradient DNA chips with 20 and 100 separately controllable hybridization sites have been designed and fabricated by using conventional microelectronic processes. The structure of a $26 \times 26 \mathrm{~mm}$ thermal gradient DNA chip with 100 sites is shown diagrammatically in Figure 1A. One hundred Si-islands are formed in the silicon dioxide membrane by using an anisotropic silicon etching technique with a silicon nitride mask. The size of each Si-island is $500 \times 500 \mu \mathrm{m}$. A heater and a temperature sensor are fabricated in each Siisland by standard silicon microfabrication techniques, as shown in Figure 1, B and D. The heater is made of a diffusion layer, and the temperature sensor is based on a $\mathrm{p}-\mathrm{n}$ junction 


\section{A. Top view}

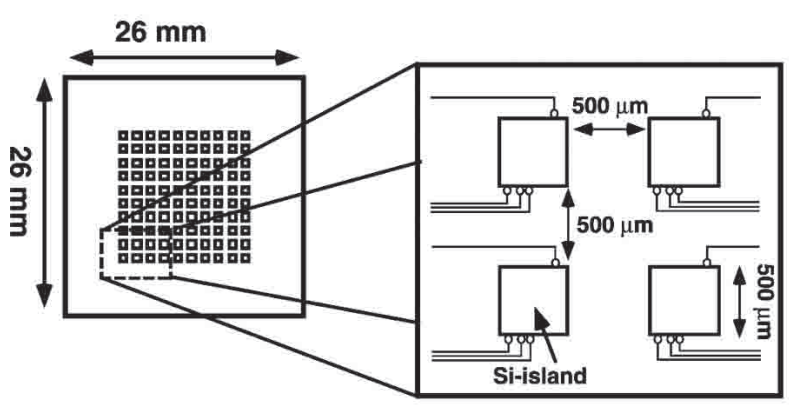

\section{B. Si-island}
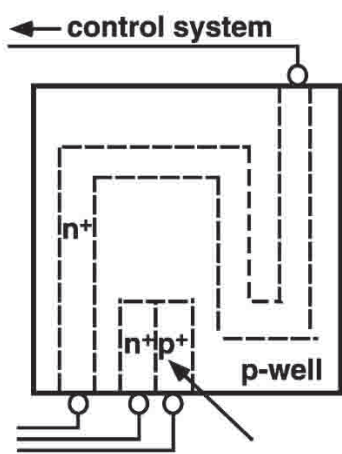

D. Si-island top view

\section{Cross-sectional view}

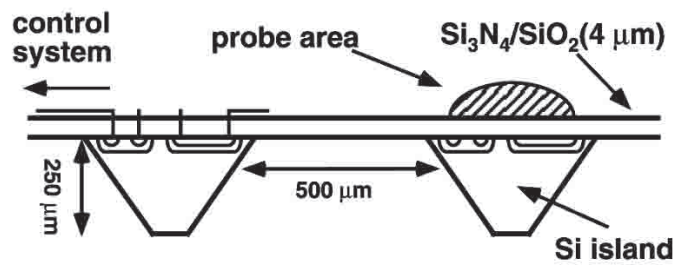

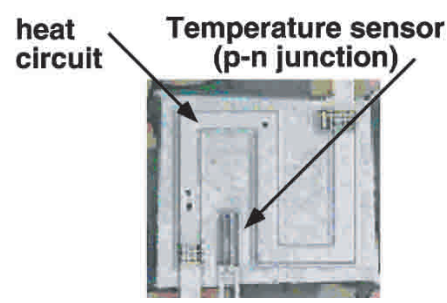

Figure 1 Structure of the thermal gradient chip. (A) Thermally controlled silicon chips were produced with both 20- and 100-island structures. The spacing and arrangement for the 100-island chip are shown. (B) The location and size of the heating and thermal sensing regions within a single island are illustrated. (C) In cross section, the relative thickness of island and thermal-isolation membrane can be seen. (D) Photographic detail of an island as shown in $B$. that represents the interface between p-type and n-type silicon, with p- and n- referring to silicon with an excess of net positive and negative charges, respectively. A cross-section of the chip is shown in Figure 1C. The height of the Si-islands is $250 \mu \mathrm{m}$, and the thickness of the multilayer film of $\mathrm{Si}_{3} \mathrm{~N}_{4} / \mathrm{SiO}_{2}$ separating them is $\sim 4 \mu \mathrm{m}$. The principle on which the new DNA chip is based is that the thermal conductivities of silicon (e.g., $148 \mathrm{~W} / \mathrm{mK}$ ) and silicon dioxide (e.g., $10.4 \mathrm{~W} / \mathrm{mK}$ ) differ significantly. Thus, one can have a relatively isothermal island of silicon surrounded by a relatively effective thermal insulator.

A photograph of the fabricated DNA chip is shown in Figure 2A. The chip is mounted on a printed circuit board and is wire-bonded to contact pads. This board, in turn is mounted in a larger board with sockets to permit cabling to the controller (Fig. 2C). The temperature control system (Fig. 2D) can be operated during both the hybridization and the washing processes. Degree of hybridization of dye-tagged targets on a chip is determined by using standard DNA chip readers (e.g., confocal scanners).

\section{Fabrication Process}

The thermal gradient DNA chips were fabricated as shown diagrammatically in Figure 2B, using n-type silicon with a resistivity of $8-12 \mathrm{ohm} / \mathrm{cm}$. Wafers were cleaned and thermally oxidized to a depth of $400 \mathrm{~nm}$. A 50-nm-thick film of silicon nitride was then deposited on the silicon dioxide layer, and p-wells were formed by ion implantation and subsequent high-temperature diffusion. After local oxidation of silicon, n-type regions were formed by ion implantation and diffusion to create heaters and temperature sensors. The n-type region for a heater is $1600 \mu \mathrm{m}$ long and 20 $\mu \mathrm{m}$ wide. Sheet resistance of the $\mathrm{n}$ type layer is $100 \mathrm{ohm} / \mathrm{cm}$. The thermal gradient chip was wire-bonded to a small chip holder board 2inch square in size (Fig. 2A). This, in turn, was inserted in a chip holder socket on a larger circuit board that was connected to the control system with ribbon cables (Fig. 2C). Analog circuitry in the controller (Fig. 2D) switched the DC heater current on and off to maintain the desired temperature. Because of the rapid response of the integrated heater and thermal sensor, temperature control was excellent $\left( \pm 0.5^{\circ} \mathrm{C}\right.$ stability and equilibration to a new elevated temperature from room temperature within $1 \mathrm{sec})$.

\section{Thermal Control and Isolation Characteristics}

\section{Computer Simulations}

The thermal isolation characteristics and performance of the chip were modeled by computer simulation by using an in-house generated algorithm using FEX (T-Tec; Hitachi High-Technology). The simulation model includes Siislands, $\mathrm{SiO}_{2}$ membrane, a sample solution, and an adhesively gasketed cover. In order to estimate the limits of temperature control and the effectiveness of thermal isolation between adjacent islands, a single island was held at a fixed temperature of $90^{\circ} \mathrm{C}$, and all other islands were designated in the simulation as unheated. Results of this simulation first as a color-coded surface plot and next as a graph of temperature versus position along a horizontal line through the centers of four neighboring islands are shown in Figure 3, A and B, respectively. Because the conductivity of silicon is high, the positions of the islands in Figure 3B are apparent as straight horizontal regions between the rapidly dropping temperatures in the adjacent silicon dioxide membrane. The unheated island adjacent to the heated island still assumes a temperature of $48^{\circ} \mathrm{C}$ owing to thermal diffusion. This thermal "leakage" could be a significant problem in certain experimental situations.

For that reason, we also investigated the properties of a different design in which heat dissipation fins $(\sim 1000 \mu \mathrm{m}$ wide by $300 \mu \mathrm{m}$ high) were located between rows and columns of islands. Because these fins intersected repeatedly with one another, they were expected to dissipate the heat generated over a large area of the chip surface. Simulated thermal profiles for such a chip with a single heated island, again held at $90^{\circ} \mathrm{C}$, are shown in Figure $4 \mathrm{~B}$. In this case, even adjacent islands remain very close to ambient temperature. The addition of fins therefore was expected to do an excellent job of thermally isolating adjacent islands from one another. Depending on the application, either of these two designs might be preferable. The plain chip permits easier integration of complex circuitry, and if one were to conduct experiments in 

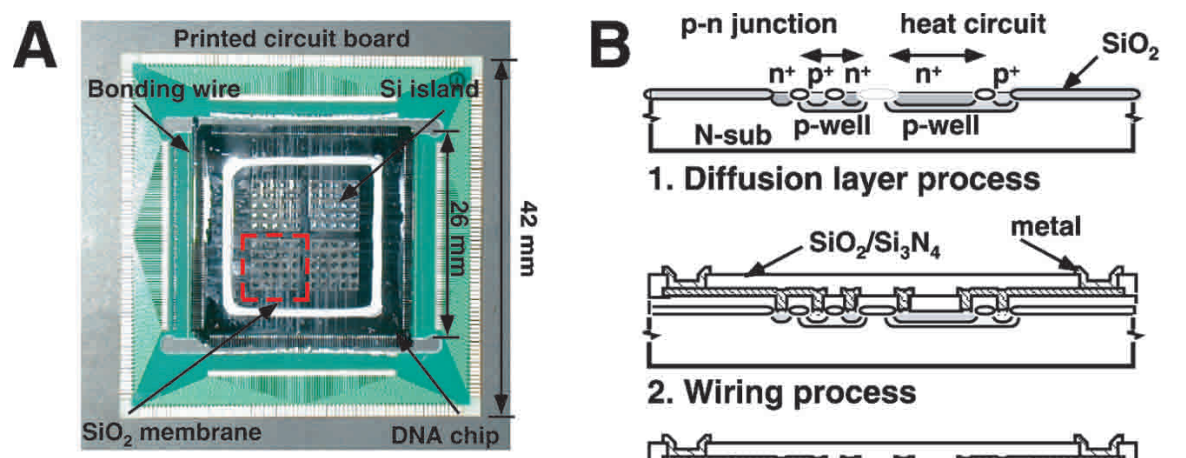

1. Diffusion layer process

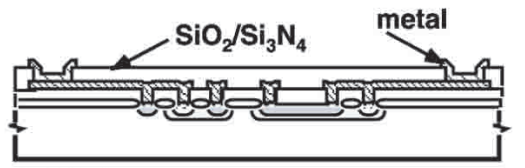

2. Wiring process
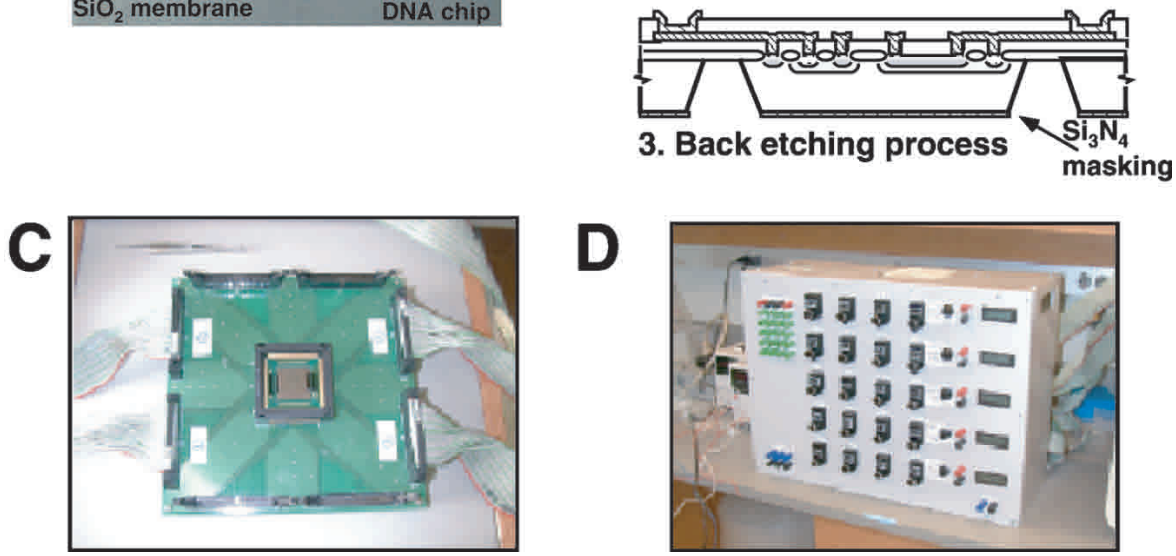

Figure 2 Manufacturing details of the thermal gradient chip and associated hardware. (A) Completed thermal gradient chip wire-bonded to a small printed circuit board for testing. The silicon islands and supporting silicon dioxide support structure are visible in the center. (B) Schematic diagram showing in cross-section several details of the chip manufacturing process. (C) The smaller board is mounted in the larger board shown here, which provides buffering and cable connections between chip and thermal controller. $(D)$ This prototype thermal controller was designed to provide individual control over temperature in 20 silicon islands simultaneously. It was used to carry out thermal isolation and response tests, as well as the hybridization experiments described here.

which adjacent islands differed from one another by, for example, no more than $5^{\circ} \mathrm{C}$, such a design would be perfectly acceptable. On the other hand, the finned chip also provides stiffening and support to the fragile silicon dioxide membrane structure. This would make the thermal gradient chip more robust and would keep the islands more co-planar, an important consideration when a confocal scanner with a small depth of field is being used for chip analysis.

\section{Experimental Results}

The thermal isolation characteristics of an actual 100-island chip with the unfinned heat dissipators are shown in Figure 3C. Only one island (A) was heated, in this case to $45^{\circ} \mathrm{C}$ (left image). With such a low temperature, the temperatures of neighboring Si-islands remained near ambient temperature $\left(20^{\circ} \mathrm{C}\right)$. However, when the four islands (B-E in Fig. 3C, right image) were heated to $45^{\circ} \mathrm{C}$ simultaneously, the temperature of the unheated central island (A) was found to increase to $29^{\circ} \mathrm{C}, \sim 9^{\circ} \mathrm{C}$ above ambient temperature. This strong effect was not seen using the finned thermal isolator. The actual hybridization results described later were all performed with finned chips.

The temperature-sensing characteristic of a $\mathrm{p}-\mathrm{n}$ junction is shown in Figure 3D, which demonstrates a reasonably linear relationship between the junction voltage and temperature. Tests on the overall operation of a gradient chip by using the sensor, heater, and control system gave excellent results. A time series of thermal imaging photographs similar to those presented in Figure 3C (data not shown) demonstrated that the temperature of an island would respond to programmed temperature changes within a matter of seconds.

\section{Probe Attachment}

Several different surface chemistries that created reactive-surface amino groups were evaluated for attachment of dye-tagged aminomodified oligonucleotide probes (20- to 25-mers) to the silicon nitride surface of the thermal gradient chip. These included use of dendrimers, polylysine, and 3-(2aminoethylamino) propyl trimethoxy silane (AEPTES) surface treatments followed by surface treatment with phenylene diisothiocyanate (PDC). After probe deposition, free PDC surface groups were blocked with glycine treatment. Those results showed use of AEPTES silane-coated surfaces to be the most straightforward and to not require a 2-week "curing" time, which was needed for the dendrimer and polylysine-treated surfaces for optimal probe attachment (Graves et al. 1998; Sanguedolce et al. 1999; Fortina et al. 2000; Pastinen et al. 2000; Cutler et al. 2001). Therefore, all subsequent hybridizations were done by using AEPTES-surface-mediated probe depositions.

\section{Hybridization}

We next evaluated utility of the thermal gradient chip for detection of various SNPs in genomic DNA. Four different loci were typed. Two SNPs in the factor VII gene $(353 \mathrm{G} \rightarrow \mathrm{A}$ and $-122 \mathrm{C} \rightarrow \mathrm{T}$ ) were interrogated by first attaching aminomodified oligonucleotide probes corresponding to normal and mutant alleles at separate array registers (Pollak et al. 1996; van't Hooft et al. 1999). Three different dye-tagged PCR targets representing the three different genotypes $(\mathrm{N} / \mathrm{N}, \mathrm{N} / \mathrm{M}$, and $\mathrm{M} / \mathrm{M}$ ) at these two polymorphic sites were generated from genomic DNA samples. PCR products were heat-denatured and annealed to three different chips. Chips contained rows of spots in which each row was thermally isolated at one of five different temperatures (Fig. 4A). In this way, effects of hybridization temperature on totally complementary and single-base mismatched targets annealing to immobilized probes could be monitored readily. The five different temperatures were selected based on estimated $\mathrm{Tm}$ values for probe/target annealing (Table 1), and each row contained duplicate spots of normal and mutant oligonucleotides, resulting in a $4 \times 5$ matrix (Fig. 4 A). 
A

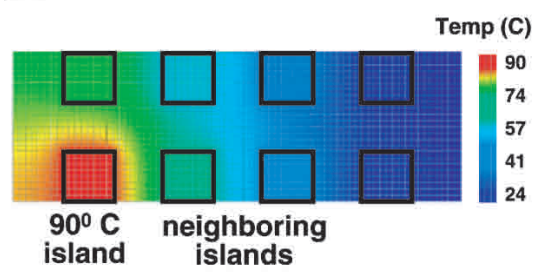

C

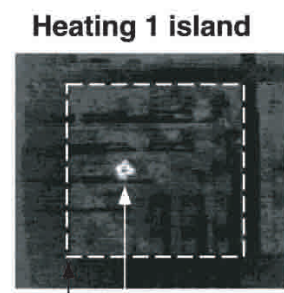

island $\mathbf{A}$

$\mathrm{SiO}_{2}$ membrane
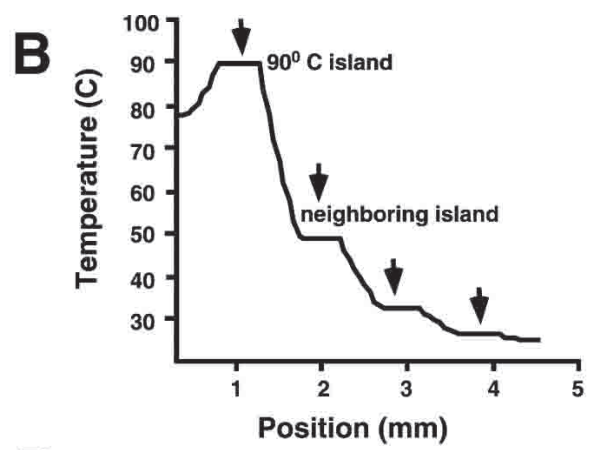

D

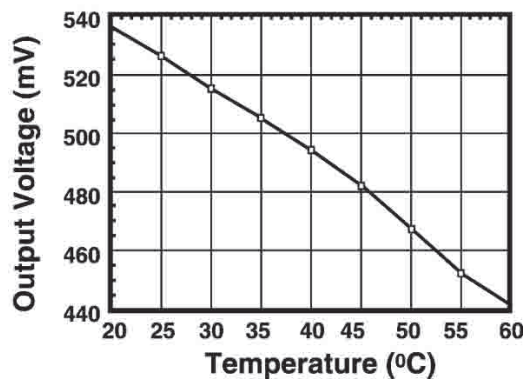

Figure 3 Thermal characteristics of the thermal gradient chip. $(A)$ When a single island is heated on an unfinned chip, the temperatures of surrounding unheated islands are affected (simulation by mathematical model). (B) A plot of temperature versus position for $A$ clearly shows isothermal islands, and the steep temperature drops between them in the insulating membrane. (C) When four islands surrounding an unheated island are heated (right), their combined effect on the temperature of the central island is much greater than when a single island is heated (left; actual thermal image of unfinned chip; see text for details). (D) The voltage-versus-temperature characteristics of the thermal sensor are fairly linear over the temperature range of interest for hybridization.

Results of target hybridization demonstrate ability to distinguish the three different genotypes. For example, results for interrogation of the $353 \mathrm{G} \rightarrow \mathrm{A}$ SNP (Fig. 5, top three panels) show selective hybridization of the dye-tagged N/N target to the corresponding normal oligonucleotide (red line in upper left panel). Maximal annealing occurred at $58^{\circ} \mathrm{C}$, with a $20.65: 1$ ratio in signal intensities for annealing of dye-tagged $\mathrm{N} / \mathrm{N}$ matched targets to matched $(\mathrm{N})$ versus single-base mismatched $(\mathrm{M})$ probes. Ratios at the five different temperatures were $8.95\left(50^{\circ} \mathrm{C}\right), 4.68\left(54^{\circ} \mathrm{C}\right), 20.65\left(58^{\circ} \mathrm{C}\right), 18.92\left(62^{\circ} \mathrm{C}\right)$, and $5.87\left(66^{\circ} \mathrm{C}\right)$, indicating ability to distinguish between matched and single-base mismatched annealings at all five different temperatures for this particular genotype and this particular locus. As expected, dye-tagged targets from N/M heterozygotes (middle panel) annealed equally to both normal and mutant oligonucleotides at $58^{\circ} \mathrm{C}$, whereas dye-tagged $\mathrm{M} / \mathrm{M}$ targets showed preferential annealing to the mutant oligonucleotide spots (right panel). Distinction between normal and mutant-bound oligonucleotides by $\mathrm{M} / \mathrm{M}$ targets was not as great as with $\mathrm{N} / \mathrm{N}$ targets, owing to detectable annealing of $\mathrm{M} / \mathrm{M}$ targets to the normal oligonucleotide spots. Despite this, the thermal chip was able to distinguish clearly between the three different genotypes at this locus.

Results for the factor VII -122 SNP (Fig. 5, lower three panels) demonstrate a different optimal temperature for annealing $\left(\geq 50^{\circ} \mathrm{C}\right)$ compared with that of the $353 \mathrm{SNP}$. Reasons for this difference are not obvious and would not have been predicted based on sequence comparison, GC content, or Tm of the two different loci. The higher temperature optimum for the 353 SNP may be related to the high $\mathrm{G} / \mathrm{C}$ content of the region surrounding the SNP. This underscores the utility of the thermal chip in facilitating experimental definition of the optimal temperature for genotyping different SNPs. Again, distinction between the three different genotypes was achieved for this locus by hybridization at $50^{\circ} \mathrm{C}$, with intensity ratios for N/M oligonucleotide spots of $0.5: 1,1.28: 1$, and $2.6: 1$ for $\mathrm{M} / \mathrm{M}, \mathrm{M} / \mathrm{N}$, and N/N genotypes, respectively.

We next genotyped two alleles (H63D and C282Y) associated with hereditary hemochromatosis, which is one of the most common genetic diseases in whites (Adams 2002). Results of the thermal chip analysis for genotyping the H63D mutation are shown in Figure 6 (upper three panels), demonstrating unambiguous typing of the three different genotypes. Temperature optimum for annealing of $\mathrm{N} / \mathrm{N}$ dye-tagged targets to normal oligonucleotide spots peaked $\sim 54^{\circ} \mathrm{C}$ with signal intensity ratios of normal to mutant oligonucleotide spots of $3.6: 1$ at $50^{\circ} \mathrm{C}$ and $3.3: 1$ at $54^{\circ} \mathrm{C}$ (left panel). Corresponding ratios for annealing of N/M dye-tagged targets were $0.8: 1$ and $0.9: 1$ at $50^{\circ} \mathrm{C}$ and $54^{\circ} \mathrm{C}$ (middle panel), respectively; whereas those for the $\mathrm{M} / \mathrm{M}$ target were $0.08: 1$ and $0.03: 1$ at those two temperatures (right panel).

One of the most interesting observations that can be made about the results seen on these four loci is related to the determination of optimum hybridization temperature. We had expected to see particular temperatures at which the fluorescence signals of either normal or mutant homozygous targets $(\mathrm{N} / \mathrm{N}$ or $\mathrm{M} / \mathrm{M}$ ) on a given pair of probes (normal and mutant) would have optimal separation. Instead, what was observed in most cases was that the fluorescence-versustemperature curve was similar on both probes. For example, in the C282 N/N results (Fig. 6, lower left panel), the two curves parallel each other rather closely. Therefore, any temperature between $45^{\circ} \mathrm{C}$ and $60^{\circ} \mathrm{C}$ would be roughly equivalent for homozygote discrimination. In the $\mathrm{C} 282 \mathrm{M} / \mathrm{M}$ results (Fig. 6 , lower right panel), the behavior is similar, with the exception that $60^{\circ} \mathrm{C}$ would not give good discrimination. However, the real value of temperature optimization can be seen with heterozygote samples. A temperature of $48^{\circ} \mathrm{C}$ gives virtually identical signals for the C282 N/M sample (Fig. 6, lower middle panel), a desirable result, whereas homozygote discrimination (both $\mathrm{N} / \mathrm{N}$ and $\mathrm{M} / \mathrm{M}$ ) is still excellent at this temperature. Similarly, for the 353 locus, $58^{\circ} \mathrm{C}$ gives identical signals for the N/M sample and correctly identifies N/N and $\mathrm{M} / \mathrm{M}$ samples at this temperature.

The $\mathrm{H} 63$ locus shows that either $54^{\circ} \mathrm{C}$ or $58^{\circ} \mathrm{C}$ would be good choices based on the N/M results, and again, the N/N and $\mathrm{M} / \mathrm{M}$ results would be unambiguous and correct at these 
A

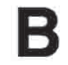

Temp ( $\left.{ }^{\circ} \mathrm{C}\right)$

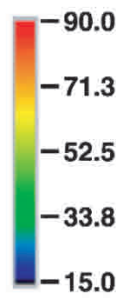

$-15.0$
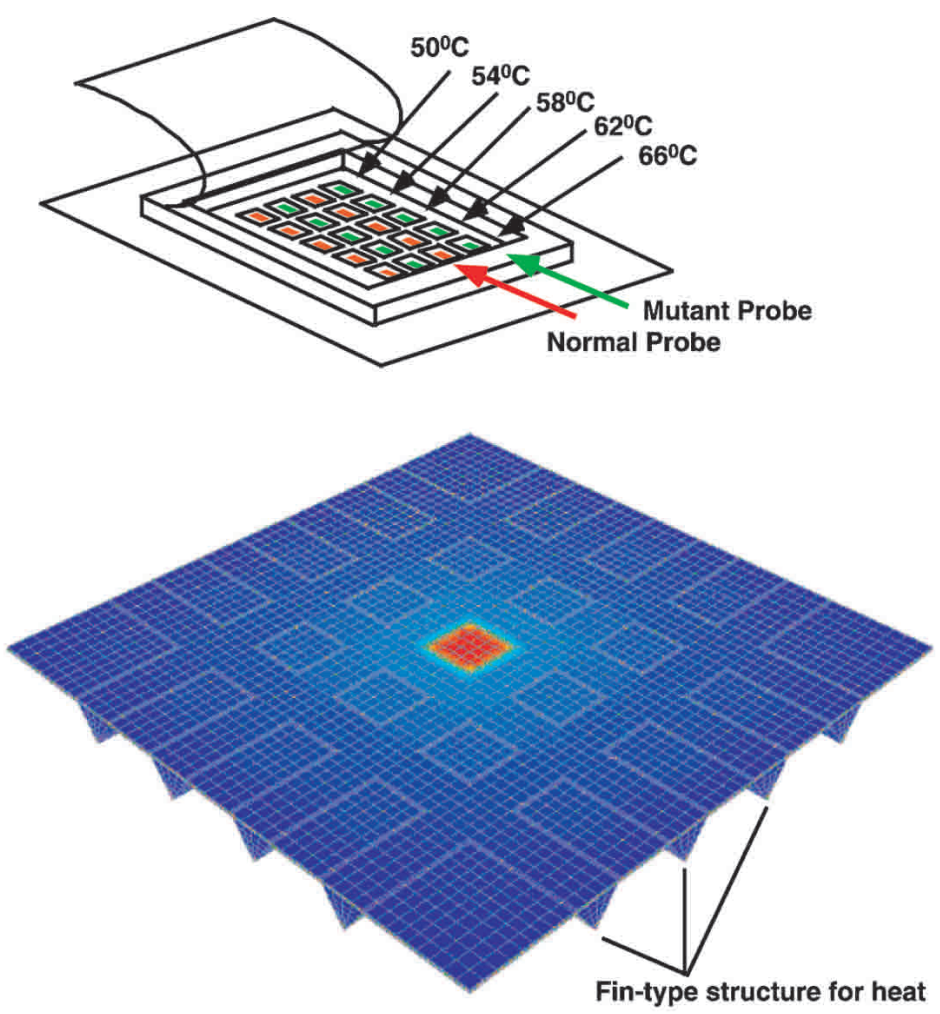

dissipation

Figure 4 Experimental design for genotyping studies and thermal dissipation effects of added fins. (A) For hybridization experiments, islands were controlled so that their temperatures increased monotonically in adjacent columns. Normal and mutant probes for a given allele were placed in duplicate in adjacent rows. $(B)$ When heat dissipation fins were constructed between islands, the thermal isolation between adjacent islands was significantly improved. (mathematical simulation; cf. Fig. 3A and refer to text for details)

temperatures. Only the -122 sample does not follow this trend. In this case, the N/M results are similar throughout the temperature range. One would probably choose the lowest temperature, $50^{\circ} \mathrm{C}$, as the optimal one in this case, based on homozygote behavior. However, it is possible that our choice of test temperatures was flawed here and that a still lower temperature would have shown a crossover for the N/M sample, whereas the homozygote signal differences improved still more. It is interesting to note that based on our empirical criteria, the optimal temperatures increase in the order $(-122$ or $\mathrm{C} 282$ ) at $\sim 48^{\circ} \mathrm{C}$ to $50^{\circ} \mathrm{C}, \mathrm{H} 63$ at $54^{\circ} \mathrm{C}$ to $58^{\circ} \mathrm{C}$, and 353 at $58^{\circ} \mathrm{C}$. However, the predicted melting points for perfectly matched probe/target pairs increase in the order $\mathrm{H} 63$ at $51^{\circ} \mathrm{C}$, $\mathrm{C} 282 \mathrm{Y}$ at $54^{\circ} \mathrm{C}$ to $57^{\circ} \mathrm{C}, 353$ at $57^{\circ} \mathrm{C}$ to $60^{\circ} \mathrm{C}$, and -122 at $62^{\circ} \mathrm{C}$ to $65^{\circ} \mathrm{C}$. There is not a good correlation between predicted and observed temperatures, once again showing how a temperature-controlled hybridization chip could be a valuable experimental tool. The clearest example of this is the -122 locus, which has a very high predicted melting point, whereas data show that fluorescence signals are vanishing and becoming indistinguishable as temperature approaches this value.

\section{DISCUSSION}

We have developed a new DNA chip in which the temperature of each DNA probe location can be controlled independently. Simulation experiments revealed that temperature dif- ferences up to at least $70^{\circ} \mathrm{C}$ could be maintained between Si-islands on the chip, provided that a finned isolation structure is used. For small temperature differences between adjacent islands, such as those we used in the hybridization experiments, an unfinned structure is acceptable. We fabricated the prototype chip and evaluated its characteristics. The temperaturesensing characteristic of the $\mathrm{p}-\mathrm{n}$ sensor is linear, so the temperature of the Si-island can be detected and controlled by using a simple function of the voltage of the $p-n$ junction.

Because it is likely that no more than five or 10 different temperatures would be used in any experiments, the most logical design for the thermal gradient chip would be a relatively small number of large islands. These could be spotted with hundreds of different sequences at each island, provided that appropriate spotting equipment was available. Because of the relative fragility of the chip surface, a piezoelectric deposition device would be preferable to the pin-type spotters.

By using this new DNA chip, DNA probes can be positioned on the chip so that their expected hybrid melting temperatures are grouped according to island temperature. In this way, neighboring island temperatures for different loci could change in a monotonic fashion to avoid dramatic differences in island temperature that might affect neighboring islands. Hybridization between a probe and target then can be performed at the desired optimal temperature for that specific sequence. Such optima can be found in preliminary experiments in which probes are placed on several different islands and annealing is done at temperatures spanning the range of interest, as we have shown here. Proper temperature choice allows one to unambiguously distinguish between the three different target genotypes. Our results show different optimal temperatures for different loci, which would not have been obvious from GC sequence content of perfect matches for bound normal or mutant oligonucleotide probe/target duplexes. Once each optimal temperature is experimentally defined, unknown samples can be typed with confidence. In retrospect, it is not particularly surprising that observed melting temperatures differed significantly from predicted. Targets used for annealing were doublestranded PCR products rather than single-stranded 20- to 25mer complementary oligonucleotides, which are used to determine melting temperature.

Perhaps more important than the use of the thermal gradient chip for clinical analyses is its potential use as a discovery tool. Optimum hybridization and washing conditions can be investigated readily by spotting identical probes on different islands and subjecting them to different thermal condi- 
tions, whereas other aspects of the protocol remain unchanged. We and others have noted that significant chipto-chip variations are seen in hybridization experiments because of uncontrollable differences in conditions or protocols during slide preparation, spotting, hybridization, and/or washing steps. A single chip system will help to minimize such variables.

Our new type of DNA chip based on arrays of thermally isolated chip islands has been shown to be effective for genotyping. Unlike other types of microarray chips, it will allow multiplex loci typing using different optimal temperatures for each locus on the same chip. This should facilitate clinical testing and lead to a lower level of false-positives/negatives because each locus would be thermally adjusted for optimal genotyping.

\section{METHODS}

\section{Fabrication}

A summary of the microfabrication processes used to create the chip used in our experiments is as follows: p-type wells first were created in the silicon wafer. To do this, silicon dioxide was deposited by chemical vapor deposition (CVD), whereas photolithography was used to create the well pattern that was dry etched into the $\mathrm{SiO}_{2}$ (process 1 ). Boron was then diffused into the patterned wafer at high temperature to create the wells, and the $\mathrm{SiO}_{2}$ was removed with hydrofluoric acid. Next, the heater and sensor were created by repeating process 1 twice with two different patterns. Phosphorous was diffused the first time to create an n-type layer. This was followed by process 1 again and boron diffusion in a third pattern to create a p-type layer. The island heater was formed by the n-layer circuitry and the $\mathrm{p}-\mathrm{n}$ junction of the temperature sensor by the combination of these two processes. Next, aluminum connections to the circuitry were added by evaporation with appropriate masking and removal steps. The top surface of the chip was completed by CVD of supporting and protective $\mathrm{SiO}_{2}$ and $\mathrm{SiN}$ layers. Next, $\mathrm{SiN}$ was deposited on the back surface of the chip, and the island structure was pat- terned by photoresist masking and dry etching. The finned structure was also created at this time (when desired). Finally, excess silicon was removed by etching with $\mathrm{KOH}$.

\section{Attachment Chemistry}

Several methods were investigated for attachment of oligonucleotides to the chip surface, including dendrimer, polylysine, and APTES-type chemistries (Graves et al. 1998; Sanguedolce et al. 1999; Fortina et al. 2000; Su et al. 2002). All solvents, including water, were HPLC grade. For experiments described here, AEPTES surface treatment was used as follows: Chips were briefly washed in ethanol and then dipped into water (MilliQ System, Millipore, Inc.) for 1 to 2 min. Just before use, a solution of $2 \%(\mathrm{v} / \mathrm{v})$ AEPTES in water was prepared. Chips were soaked in this solution for $2 \mathrm{~h}$, washed by briefly dipping in fresh water, and baked at $110^{\circ} \mathrm{C}$ for $1 \mathrm{~h}$. Next, they were washed by dipping briefly in ethanol. A solution of $0.2 \%(\mathrm{w} / \mathrm{v})$ PDC in solvent consisting of $10 \%$ pyridine and $90 \%$ dimethyl formamide (DMF; v/v) was prepared. The chips were placed in this solution for $2 \mathrm{~h}$ and then washed for 5 min each, respectively, in methanol and acetone. This was followed by a 5 -min bake at $110^{\circ} \mathrm{C}$, after which activated slides were ready to accept amino-modified oligonucleotide probes.

Base sequences and chemical modifications of the oligonucleotides used are listed in Table 1. Oligonucleotides were dissolved in water at a concentration of $100 \mu \mathrm{M}$. Ten microliters then were mixed with $10 \mu \mathrm{L}$ of $2 \times$ microspotting solution (TeleChem International, Inc.) and spotted with a robotic deposition device, as previously described (Graves et al. 1998). For some studies, lower concentrations were investigated. Small volumes $(20 \mathrm{~nL})$ were spotted on each island in the desired pattern, and the chip was kept at $55^{\circ} \mathrm{C}$ in an atmosphere of $100 \%$ humidity overnight to complete the coupling reaction. Because some of the subsequent washing solutions, especially glycine, had a strong corrosive effect on the aluminum bonding wires, subsequent washing was done by pipetting various solutions onto the chip surface, followed by solution removal by suctioning. A Hybaid EasySeal gasket (MJ Research, Inc.) was used on the chip surface (without cover) to

Table 1. PCR Primers, Product Size (bp), and Array-Bound Allele-Specific Oligonucleotide Probes Used for Genotyping

\begin{tabular}{|c|c|c|c|c|c|}
\hline Locus & Function & Sequence & Size (bp) & GC\% & $\mathbf{T}$ \\
\hline \multirow[t]{4}{*}{-122} & F-PCR & 5'-Cy5-GGGGTCACCTGACCTTTCTC-3' & 178 & & \\
\hline & R-PCR & $5^{\prime}$-GACTGACGGGCAAAGTTCTC-3' & & & \\
\hline & ASO-122-N & $5^{\prime}$ - CGTCCTCTGAACACCCCAGCT-3' & & 62 & 62 \\
\hline & ASO-122-M & $5^{\prime}$ - CGTCCTCTGA $\underline{\overline{\mathbf{G}}} \mathrm{CACCCCAGCT-3}$ & & 67 & 65 \\
\hline \multirow[t]{4}{*}{ R353Q } & F-PCR & $5^{\prime}-$ TCTGTGCCGGCTACTCG-3' & 150 & & \\
\hline & $\mathrm{R}-\mathrm{PCR}$ & $5^{\prime}$-СУ5-TGTACACCCCAAAGTGGCC-3' & & & \\
\hline & ASO R353Q-N & 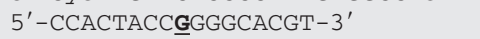 & & 71 & 60 \\
\hline & ASO R353Q-M & 5'-CCACTACC互GGGCACGT-3' & & 65 & 57 \\
\hline \multirow[t]{4}{*}{ C282Y } & F-PCR & $5^{\prime}-$ TGGCAAGGGTAAACAGATCC-3' & 390 & & \\
\hline & R-PCR & $5^{\prime}$-СY5-СTCAGGCACTCCTCTCAACC-3' & & & \\
\hline & ASO $282-N$ & $5^{\prime}$-AGATATACGTGCCAGGTGGAG- $3^{\prime}$ & & 52 & 57 \\
\hline & ASO 282-M & $5^{\prime}$-AGATATACGTA & & 47 & 54 \\
\hline \multirow[t]{4}{*}{ H63D } & F-PCR & 5'-ACATGGTTAAGGCCTGTTGC-3' & 208 & & \\
\hline & R-PCR & 5'-Cy5-GCCACATCTGGCTTGAAATT-3' & & & \\
\hline & ASO-63-N & $5^{\prime}$-GTTCTATGATCATGAGAGTCG-3' & & 43 & 51 \\
\hline & ASO-63-M & $5^{\prime}$ - GTTCTATGAT $\mathbf{\mathbf { G }}$ ATGAGAGTCG-3' & & 43 & 51 \\
\hline
\end{tabular}




\section{$\mathrm{N}-\mathrm{ASO}=\mathrm{M}-\mathrm{ASO}$}

$353 \mathrm{~N} / \mathrm{N}$
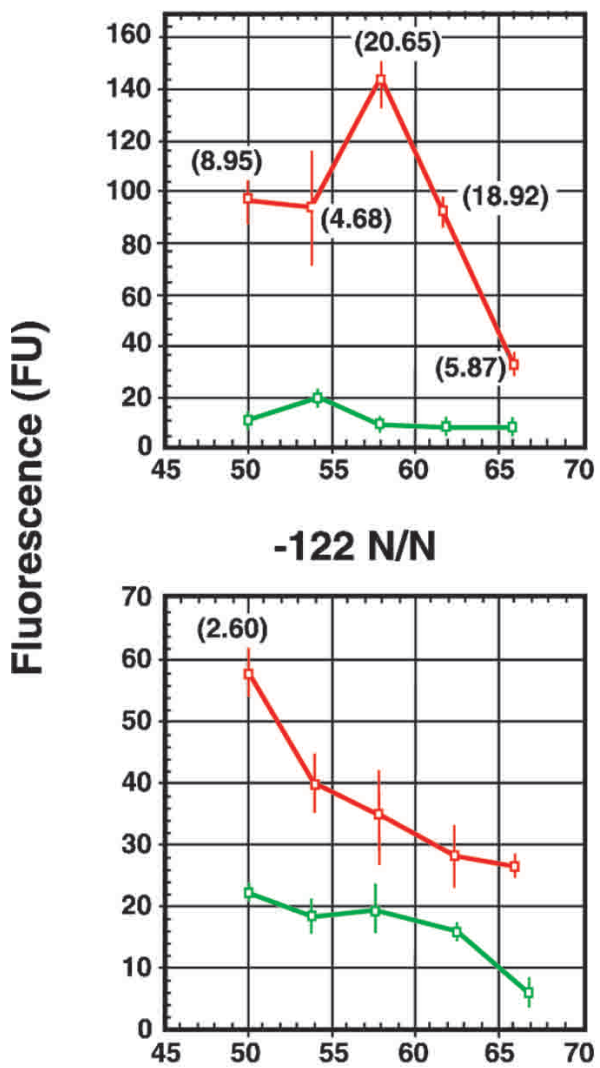

353 N/M

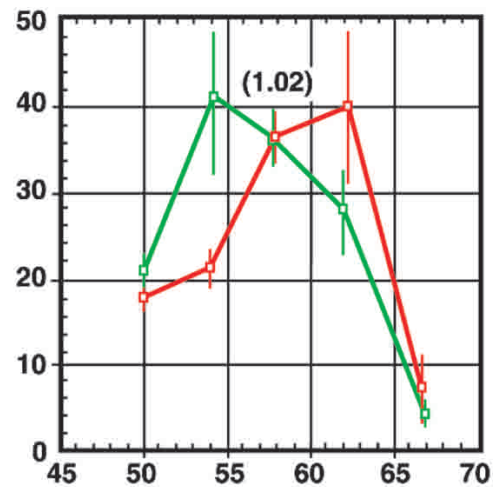

$-122 \mathrm{~N} / \mathrm{M}$

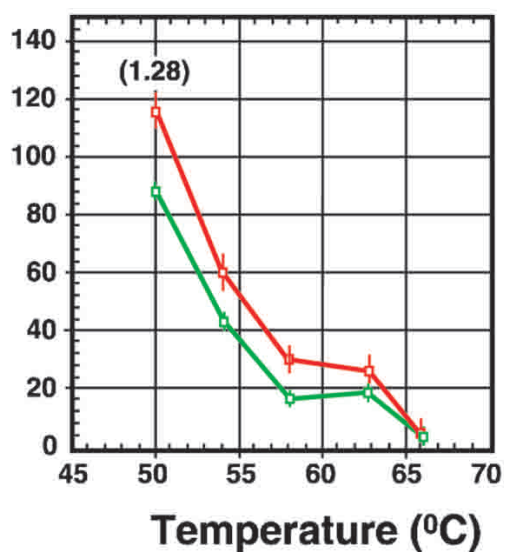

$353 \mathrm{M} / \mathrm{M}$

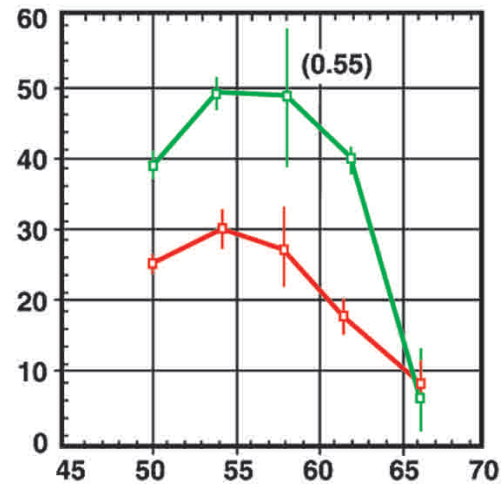

$-122 \mathrm{M} / \mathrm{M}$

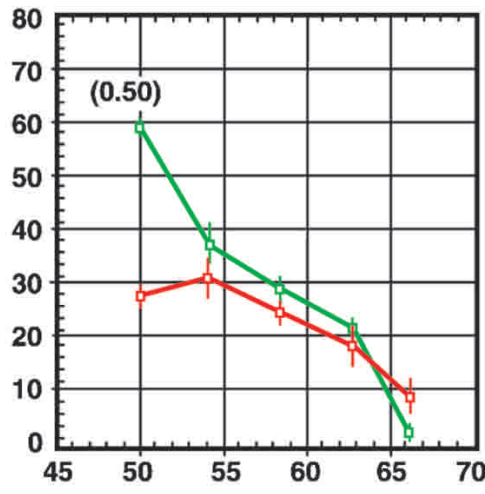

Figure 5 Genotype analyses for two SNPs in the factor VII gene by using a thermal gradient chip. Fluorescence units ( $y$-axis) as a function of chip island temperature ( $x$-axis) are shown for hybridization of Cy 5-labeled, denatured PCR, and solution-phase targets to chip-bound normal (N-ASO, red) or mutant (M-ASO, green) oligonucleotide probes. Genomic DNA from individuals either heterozygous (N/M, middle panels), homozygous wild type (N/N, left panels), or homozygous mutant (M/M, right panels) encompassing either the G353A (upper three panels) or C-122T (lower three panels) SNPs in the factor VII gene were amplified by PCR. Samples then were heat denatured and annealed to chips containing the five different thermally isolated islands. Chips were washed and scanned as described in Methods. Numbers in brackets refer to the ratio of intensities of annealing of labeled targets to normal (red)/mutant (green) probe spots on the array.

further confine solutions and ensure no fluid contact with the bonding wires. The washes, conducted at $55^{\circ} \mathrm{C}$, were as follows: $5 \times$ SSC $+0.01 \%(\mathrm{w} / \mathrm{v})$ SDS, followed by a brief wash with water for typing R353Q. For -122 , H63D, and C282Y, an additional wash of $0.5 \times$ SSC $+0.1 \%(\mathrm{w} / \mathrm{v})$ SDS was added. Next, $1 \mathrm{M}$ glycine ( $\mathrm{pH}$ 7.5) was pipetted onto the chip at room temperature, and the solution was heated to $55^{\circ} \mathrm{C}$ for $1 \mathrm{~h}$ to inactivate any remaining PDC groups. Chips were washed briefly with water at $55^{\circ} \mathrm{C}$, then $3 \times$ SSC was pipetted onto the chips and allowed to remain for $30 \mathrm{~min}$ at $55^{\circ} \mathrm{C}$, which was followed by a brief wash with water at $55^{\circ} \mathrm{C}$.

\section{Preparation of Dye-Tagged Targets, Annealing, Washing, and Scanning}

Cy5-labeled PCR target DNA for genotyping was generated from genomic DNA that was isolated from peripheral blood by using a standard protocol (Gentra System, Inc.) using primer pairs listed in Table 1. PCR products were purified by using QiaQuick PCR purification kit (Qiagen, Inc.), denatured at $95^{\circ} \mathrm{C}$, and $0.5 \mathrm{ng} / \mu \mathrm{L}$ were used for 14 - to 16 -h hybridization in $5 \times$ SSC containing $0.01 \%(\mathrm{w} / \mathrm{v})$ SDS at a variety of islandcontrolled temperatures. Washings were performed by using $5 \times$ SSC containing $0.01 \%(\mathrm{w} / \mathrm{v}) \mathrm{SDS}$ at $50^{\circ} \mathrm{C}$, and chip scanning was accomplished on a GSI-5000 confocal scanner (Packard BioScience). Because of the flexibility of the supporting $\mathrm{SiO}_{2}$ membrane structure, the islands did not all lie in the same focal plane. Thus, several consecutive scans were needed to achieve good focus for all islands. Measurements were made on the best focused image of each island.

\section{ACKNOWLEDGMENTS}

We thank Drs. M. Terada, of Hitachi ULSI Systems Co., Ltd., and K. Miyake, of Hitachi, Ltd., for their help and useful discussions. This work was supported in part by grants from the NIH-NCI (R21CA83220-01A1 to P.F. and S.S.) and NIH-NHLBI (P60-HL38632 to P.F., P.W., and L.J.K.) and by a Research Sponsored Agreement between Hitachi High Technologies and The Children's Hospital of Philadelphia (P.F.).

The publication costs of this article were defrayed in part by payment of page charges. This article must therefore be 


\section{N-ASO M-ASO}
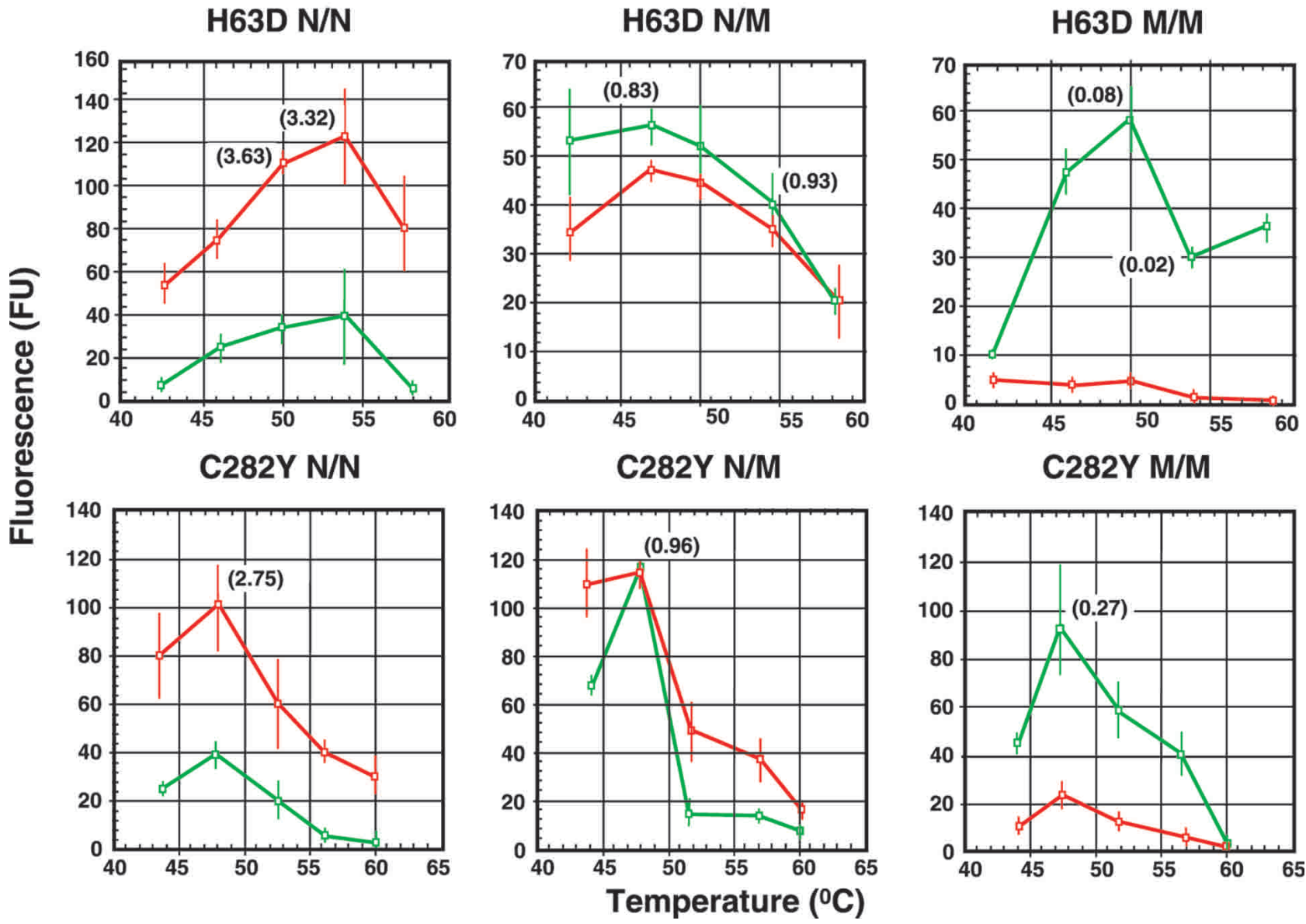

Figure 6 Genotype analyses for H63D and C282Y mutations in the human hemochromatosis gene by using the thermal gradient chip. Experimental details were as described in Fig. 5 with the exception that PCR products that encompassed the H63D and C282Y mutations were used with the indicated chip island temperatures. Numbers in brackets refer to the ratio of intensities of annealing of labeled targets to normal (red)/mutant (green) probe spots on the array.

hereby marked "advertisement" in accordance with 18 USC section 1734 solely to indicate this fact.

\section{REFERENCES}

Adams, P.C. 2002. Population screening for hemochromatosis: Are we finding people with a disease or a biochemical curiosity? Semin. Gastrointest. Dis. 13: 89-94.

Cai, W.-W., Mao, J.-H., Chow, C.-W., Damani, S., Balmain, A., and Bradley, A. 2002. Genome-wide detection of chromosomal imbalances in tumors using BAC microarrays. Nat. Biotechnol. 20: 393-396.

Carter, T.A., Del Rio, J.A., Greenhall, J.A., Latronica, M.L., Lockhart, D.J., and Barlow, C. 2001. Chipping away at complex behavior: Transcriptome/phenotype correlations in the mouse brain. Physiol. Behav. 73: 849-857.

Case-Green, S.C., Mir, K.U., Pritchard, C.E., and Southern, EM. 1998. Analyzing genetic information with DNA arrays. Curr. Opin. Chem. Biol. 2: 404-410.

Cutler, D.J., Zwick, M.E., Carrasquillo, M.M., Yohn, C.T., Tobin, K.P., Kashuk, C., Mathews, D.J., Shah, N.A., Eichler, E.E., Warrington, J.A., et al. 2001. High-throughput variation detection and genotyping using microarrays. Genome Res. 11: 1913-1925.

Dong, S., Wang, E., Hsie, L., Cao, Y., Chen, X., and Gingeras, T.R. 2001. Flexible use of high-density oligonucleotide arrays for single-nucleotide polymorphism discovery and validation. Genome Res. 1: 1418-1424.

Fan, J.B., Chen X., Halushka, M.K., Berno, A., Huang, X., Ryder, T., Lipshutz, R.J., Lockhart, D.J., and Chakravarti, A. 2000. Parallel genotyping of human SNPs using generic high-density oligonucleotide tag arrays. Genome Res. 10: 853-860.

Fortina, P., Delgrosso, K., Sakazume, T., Santacroce, R., Moutereau, S., Su, H.-J., Graves, D., McKenzie, S., and Surrey, S. 2000. Simple two-color array-based approach for mutation detection. Eur. J. Hum. Genet. 8: 884-894.

Gerry, N.P., Witowski, N.E., Day, J., Hammer, R.P., Barany, G., and Barany, F. 1999. Universal DNA microarray method for multiplex detection of low abundance point mutations. J. Mol. Biol. 292: 251-262.

Gilles, P.N., Wu, D.J., Foster, C.B., Dillon, P.J., and Chanock, S.J. 1999. Single nucleotide polymorphic discrimination by an electronic dot blot assay on semiconductor microchips. Nat. Biotechnol. 17: 365-370.

Graves, D., Su, H-J., McKenzie, S., Surrey, S., and Fortina, P. 1998. System for preparing microhybridization arrays on glass slides. Anal. Chem. 270: 5085-5092.

Hirschhorn, J.N., Sklar, P., Lindblad-Toh, K., Lim, Y.M., Ruiz-Gutierrez, M., Bolk, S., Langhorst, B., Schaffner, S., Winchester, E., and Lander, E.S. 2000. SBE-TAGS: An array-based method for efficient single-nucleotide polymorphism genotyping. Proc. Natl. Acad. Sci. 97: 12164-12169.

Jobs, M., Fredriksson, S., Brookes, A.J., and Landegren, U. 2002.

\section{Genome Research}


Effect of oligonucleotide truncation on single-nucleotide distinction by solid-phase hybridization. Anal. Chem. 74: 199-202.

Khrapko, K.R., Lysov, Y.-P., Khorlin, A.A., Ivanov, I.B., Yershov, G.M., Vasilenko, S.K., Florentiev, V.L., and Mirzabekov, A.D.A. 1991. Method for DNA sequencing by hybridization with oligonucleotide matrix. DNA Sequence 1: 375-388.

Kricka, L.J., Fortina P., Panaro N., Wilding, P., Alonso-Amigo, G., and Becker, H. 2002. Fabrication of plastic microchips by hot embossing. Lab on a Chip 2: 1-4.

Kwok, P.Y. 2001. Methods for genotyping single nucleotide polymorphisms. Annu. Rev. Genomics Hum. Genet. 2: 235-258.

Lindblad-Toh, K., Tanenbaum, D.M., Daly, M.J., Winchester, E., Lui, W.O., Villapakkam, A., Stanton, S.E., Larsson, C., Hudson, T.J., Johnson, B.E., et al. 2000. Loss-of-heterozygosity analysis of small-cell lung carcinomas using single-nucleotide polymorphism arrays. Nat. Biotechnol. 18: 1001-1005.

Lipshutz, R.J., Fodor, S.P., Gingeras, T.R., and Lockhart, D.J. 1999. High density synthetic oligonucleotide arrays. Nat. Genet. 21: 20-24.

Mei, R., Galipeau, P.C., Prass, C., Berno, A., Ghandour, G., Patil, N., Wolff, R.K., Chee, M.S., Reid, B.J., and Lockhart, D.J. 2000. Genome-wide detection of allelic imbalance using human SNPs and high-density DNA arrays. Genome Res. 10: 1126-1137.

Pastinen, T., Raitio, M., Lindroos, K., Tainola, P., Peltonen, L., and Syvanen, A.C. 2000. A system for specific, high-throughput genotyping by allele-specific primer extension on microarrays. Genome Res. 10: 1031-1042.

Pollak, E.S., Hung, H.L., Godin, W., Overton, G.C., and High, K.A. 1996. Functional characterization of the human factor VII 5'-flanking region. J. Biol. Chem. 271: 1738-1747.

Ramaswamy, S., Tamayo, P., Rifkin, R., Mukherjee, S., Yeang, C.H., Angelo, M., Ladd, C., Reich, M., Latulippe, E., Mesirov, J.P., et al. 2001. Multiclass cancer diagnosis using tumor gene expression signatures. Proc. Natl. Acad. Sci. 98: 15149-15154.

Sanguedolce, L.A., Chan, V., McKenzie, S., Surrey, S., Fortina, P., and Graves, D. 1999. Fundamental studies of DNA adsorption and hybridization on solid surfaces. In: American Chemical Society series: Intelligent materials for controlled release (eds. S. Dinh and J.
De Nuzzio), pp. 190-204. Oxford University Press, New York, NY. Shipp, M.A., Ross, K.N., Tamayo, P., Weng, A.P., Kutok, J.L., Aguiar, R.C., Gaasenbeek, M., Angelo, M., Reich, M., Pinkus, G.S., et al. 2002. Diffuse large B-cell lymphoma outcome prediction by gene-expression profiling and supervised machine learning. Nat. Med. 8: 68-74.

Sosnowski, R.G., Tu, E., Butler, W.F., O'Connell, J.P., and Heller, M.J. 1997. Rapid determination of single base mismatch mutations in DNA hybrids by direct electric field control. Proc. Natl. Acad. Sci. 94: $1119-1123$.

Su, H.-J., Surrey, S., McKenzie, S.E., Fortina, P., and Graves, D.J. 2002. Kinetics of heterogeneous hybridization on indium tin oxide surfaces with and without an applied potential. Electrophoresis 23: 1551-1557.

Syvanen, A.C. 2001. Accessing genetic variation: Genotyping single nucleotide polymorphisms. Nat. Rev. Genet. 2: 930-942.

Van't Hooft, F.M., Silveira, A., Tornvall, P., Iliadou, A., Ehrenborg, E., Eriksson, P., and Hamsten, A. 1999. Two common functional polymorphisms in the promoter region of the coagulation factor VII gene determining plasma factor VII activity and mass concentration. Blood 93: 3432-3441.

Wilding, P., Kricka, L.J., Cheng, J., Hvichia, G., and Fortina, P. 1998. Integrated cell isolation and PCR analysis using silicon microfilter-chambers. Anal. Biochem. 257: 95-100.

Yeakley, J.M., Fan, J.B., Doucet, D., Luo, L., Wickham, E., Ye, Z., Chee, M.S., and Fu, X.D. 2002. Profiling alternative splicing on fiber-optic arrays. Nat. Biotechnol. 20: 353-358.

Yuen, P.-K., Kricka, L.J., Fortina, P., Panaro, N.J., Sakazume, T., and Wilding, P. 2002. Microchip module for blood sample preparation and nucleic acid amplification reactions. Genome Res. 11: $405-412$.

Zarrinkar, P.P., Mainquist, J.K., Zamora, M., Stern, D., Welsh, J.B., Sapinoso, L.M., Hampton, G.M., and Lockhart, D.J. 2001. Arrays of arrays for high-throughput gene expression profiling. Genome Res. 11: 1256-1261.

Received September 10, 2002; accepted in revised form December 6, 2002.
Genome Research www.genome.org 


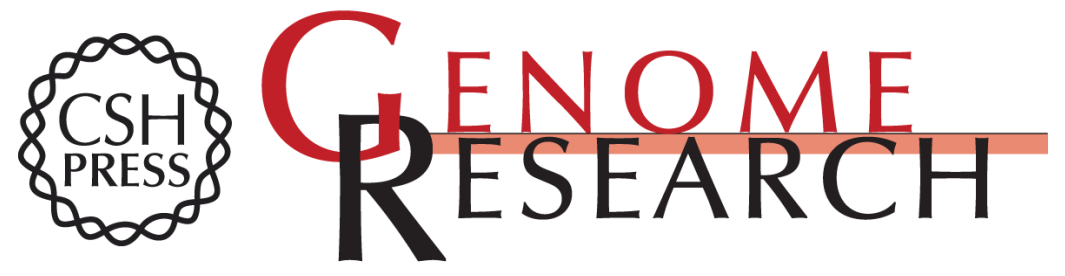

\section{Genotyping on a Thermal Gradient DNA Chip}

Tomoharu Kajiyama, Yuji Miyahara, Larry J. Kricka, et al.

Genome Res. 2003 13: 467-475

Access the most recent version at doi:10.1101/gr.790603

References This article cites 29 articles, 11 of which can be accessed free at:

http://genome.cshlp.org/content/13/3/467.full.html\#ref-list-1

\section{License}

Email Alerting Receive free email alerts when new articles cite this article - sign up in the box at the Service top right corner of the article or click here.

\section{Affordable, Accurate Sequencing.}

To subscribe to Genome Research go to: https://genome.cshlp.org/subscriptions 